\title{
Pemanfaatan Limbah Puntung Rokok Filter Sebagai Bahan Campuran Beton Ringan Berpori
}

\author{
${ }^{1}$ Agata Iwan Candra, ${ }^{2}$ Edy Gardjito, ${ }^{3}$ Yosef Cahyo, ${ }^{4}$ Andri Dwi Cahyono, ${ }^{5}$ Zendy Bima \\ Mahardana \\ 1,2,3,4,5 Fakultas Teknik Universitas Kadiri \\ e-mail : iwan_candra@unikkediri.ac.id,edygardjito@unik-kediri.ac.id, Yosef.cs@unik- \\ kediri.ac.id, adcahyono@unik-kediri.ac.id,zmahardana@unik-kediri.ac.id
}

\begin{abstract}
Waste cigarette filler waste is a waste that is difficult to recycle. Cotton fillter cigarette butts are cottonbased fibers which are lightweight, porous and easily absorb water. For the use of this waste as a substitute for overall coarse aggregate, research needs to be carried out, namely the amount of compressive strength produced by replacing coarse aggregate from cigarette butts waste, job mix used according to SNI K-125 by completely replacing coarse aggregate with cigarette butts waste „, Job mix for $1 \mathrm{~m}^{3}$ concrete consists of $276 \mathrm{~kg}$ of cement, 214 liters of water, $148.62 \mathrm{~kg}$ of cigarette butts, and $828 \mathrm{~kg}$ of sand. From the above research, the highest compressive strength at 28 days reached $K-115.56$, which means that the target for concrete paving has reached $K-100$. As for the absorption value is quite high from consecutive tests for 1/4 hours, 1 hour, 4 hours, and 24 hours produced an average value of 0.116 liters, 0.269 liters, 0.374 liters, 0.699 liters. The results of the study of concrete density with coarse aggregate of cigarette butts waste reached an average of $1831.11 \mathrm{~kg} / \mathrm{m}^{3}$, for the study the pore figures yielded an average value of 0.2854 , then the results of the porosity values obtained an average of 0.222016 .
\end{abstract}

Keywords: Lightweight Concrete, Porous Concrete, Waste Of Cigarette Filler Butts

\begin{abstract}
Abstrak
Limbah puntung rokok fillter adalah suatu limbah yang sulit untuk di daur ulang. Puntung rokok fillter berbahan dasar kapas yang merupakan serat yang memiliki sifat ringan, berpori, dan mudah menyerap air. Untuk penggunaan limbah ini sebagai pengganti agregat kasar secara menyeluruh perlu diadakan penelitian yaitu besarnya kuat tekan yang di hasilkan dengan penggantian agregat kasar dari limbah puntung rokok tersebut, job mix yang digunakan sesuai SNI K-125 dengan mengganti sepenuhnya agregat kasar dengan limbah puntung rokok,job mix untuk $1 m^{3}$ beton terdiri dari semen $276 \mathrm{Kg}$, air 214 liter, puntung rokok 148,62 Kg, dan pasir sebanyak $828 \mathrm{Kg}$. Dari penelitian di atas diperoleh nilai kuat tekan pada umur beton 28 hari tertinggi mencapai K-115,56 yang berarti telah mencapai target untuk paving beton sebesar K-100. Sedangkan untuk nilai absorsinya cukup tinggi dari pengujian berturut-turut selama 1/4 jam, 1 jam, 4 jam, dan 24 jam di hasilkan nilai rata-rata sebesar 0,116 liter, 0,269 liter, 0,374 liter, 0,699 liter. Hasil penelitian dari berat jenis beton dengan agregat kasar limbah puntung rokok mencapai rata-rata $1831,11 \mathrm{Kg} / \mathrm{m}^{3}$, untuk penelitian angka pori di hasilkan nilai rata-rata mencapai 0,2854, selanjutnya hasil nilai porositas diperoleh rata-rata mencapai 0,222016.
\end{abstract}

Kata Kunci: Beton Ringan,Beton Berpori, Limbah Puntung Rokok Fillter 


\section{PENDAHULUAN}

\subsection{Tinjauan Umum}

Beton merupakan salah satu komponen penyangga dalam sebuah konstruksi. Beton memiliki fungsi yang vital terutama untuk struktur suatu bangunan. penggunaan beton pada sebuah gedung,ruko,rumah tinggal berbeda dengan penggunaan beton untuk jalan. Pada umumnya beton memiliki tekstur yang padat dan kedap air,hal tersebut juga mempengaruhi berat jenis beton itu sendiri, berat jenis beton normal cenderung tinggi sehingga mempengaruhi beban yang di terima oleh pondasi. Selain berat jenis beton yang tinggi bahan baku pembuatan beton pun masih mengandalkan sumber daya alam, salah satunya yaitu penggunaan batu belah atau koral yang biasanya dipakai untuk campuran beton. Hal tersebut apabila terjadi secara terus menerus maka sumber daya alam dapat menipis dan akhirnya habis, maka di perlukan bahan pengganti yang di dapat dari limbah atau bahan yang sudah tidak terpakai lagi. Dalam ilmu teknik sipil inovasi sangat di butuhkan terutama untuk mengatasi permasalahan yang ada,salah satunya masalah dampak lingkungan yang diakibatkan dari penggunaan agregat atau bahan dari alam yang tidak dapat diperbarui dengan cara memanfaatkan limbah dari puntung rokok filter fillter sebgai pengganti agregat kasar. Bahan ini dipilih sebagai bahan campuran kerena mengingat di Indonesia sendiri konsumen rokok sangat banyak ,dengan adanya pengolahan limbah ini tentu akan mengurangi sampah yang di hasilkan dari para konsumen rokok, selain itu berat jenis dari puntung rokok filter sangat ringan sehingga otomatis akan mengurangi berat jenis pada beton.

\subsection{Rumusan Masalah}

Berdasarkan latar belakang masalah diatas maka dapat dikemukakan beberapa masalah sebagai berikut :

Pengaruh penggunaan limbah puntung rokok filter filter sebagai pengganti agregat kasar pada beton berpori terhadapkuat tekan, berat jenis beton, nilai angka pori , nilai porositas pada beton $\mathrm{K}-125$.

\section{METODE PENELITIAN}

\subsection{Material}

Material yang digunakan untuk pembuatan beton ini berupa Semen Portland merk Semen Gresik jenis (PC), Agregat halus (Pasir Gunung Kelud Kediri), Agregat kasar dari Limbah Puntung rokok filter Fillter yang ada di kediri,dan Air yang diambil dari PDAM Universitas Kadiri 


\subsubsection{Puntung Rokok Filter}

Banyaknya limbah puntung rokok yang terbuang tanpa penanganan lebih lanjut akan menimbulkan pencemaran lingkungan. . Kapas merupakan serat yang bisa dimanfaatkan sebagai bahan pengisi pada pembuatan material komposit. Oleh sebab itu, kapas dari puntung rokok sangat berpotensi digunakan sebagai campuran beton dengan karakteristik menyerap air.

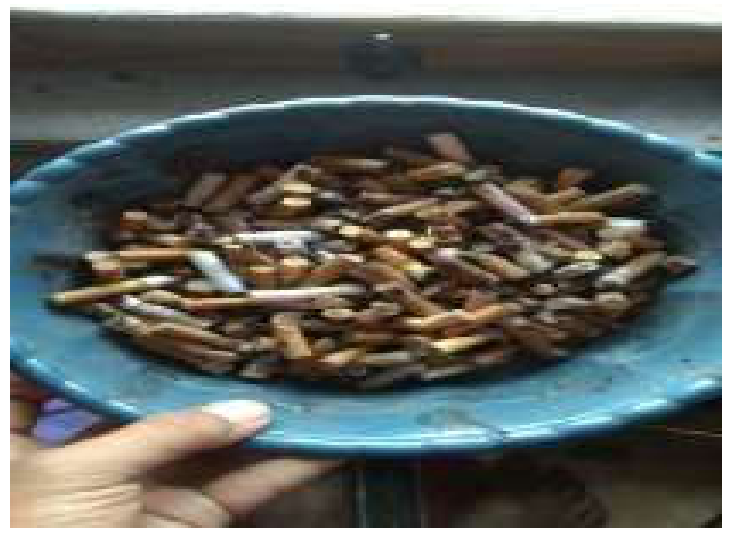

Gambar 1: Puntung rokok filter

\subsubsection{Semen Portland (PC)}

Semen adalah suatu bahan yang memiliki sifat adhesif dan kohesif yang memungkinkan melekatnya fragmen mineral menjadi suatu benda padat. Semen merupakan bahan yang dapat mengeras jika bereaksi dengan air, hal ini adalah yang dinamakan semen hidraulis. Semen portland atau biasa di sebut semen adalah bahan pengikat hidroli berupa bubuk halus yang dihasilkan dengan cara menghaluskan klinker, dengan batu gips sebagai bahan tambahan. Semen yang digunakan adalah semen portland tipe I.

\subsubsection{Air}

Air adalah bahan dasar pembuatan beton. Fungsi air dalam pembuatan beton untuk membuat semen bereaksi dan sebagai bahan pelumas antara agregat kasar dan halus. Untuk membuat semen bereaksi hanya dibutuhkan air sekitar 25\%-30\% dari berat semen tersebut. Tetapi pada kenyataan dilapangan apabila faktor air semen. Kelebihan air inilah yang berfungsi sebagai pelumas agregat, sehingga membuat adukan mudah dikerjakan. Tetapi seiring dengan semakin mudahnya pengerjaan, maka akan menyebabkan beton menjadi porus, maka kuat tekan beton juga akan menurun.

\subsubsection{Agregat Halus}

Agregat halus untuk beton dapat berupa pasir alam sebagai hasil disintegrasi alami dari batubatuan atau berupa pasir buatan yang dihasilkan oleh alat-alat pemecah batu. Agregat halus pada penelitian ini menggunakan jenis agregat halus yaitu pasir alami, pasir ini merupakan pasir alami yang diambil dari lereng gunung kelud. pasir yang diambil dari kelud termasuk ke 
dalam jenis pasir galian karena dalam pengambilannya dengan cara digali. Ditinjau dari asalnya, pasir yang dipakai dalam pengujian ini adalah pasir yang berasal dari erupsi gunung kelud. Sehingga dapat disimpulkan bahwa pasir yang digunakan adalah pasir kelud yang termasuk jenis pasir kasar.

\subsection{Pengujian Kuat Tekan Beton}

Nilai kuat tekan beton didapatkan melalui tata cara pengujian standar, menggunakan mesin uji dengan cara memberikan beban tekan bertingkat pada benda uji silinder beton (diameter 150 $\mathrm{mm}$, tinggi $300 \mathrm{~mm}$ ) sampai hancur. Untuk standar pengujian kuat tekan digunakan SNI 036805 - 2002 dan ASTM C 39/C 39M-04a.

$\mathrm{K}=\quad \mathrm{P} / \mathrm{A}$

Dimana

$\mathrm{K}=$ Kuat tekan beton $\left(\mathrm{kg} / \mathrm{cm}^{2}\right)$

$\mathrm{P}=$ Gaya tekan aksial, dinyatakan dalam newton $(\mathrm{N})$

$\mathrm{A}=$ Luas penampang melintang benda uji, dinyatakan dalam $\mathrm{cm}^{2}$

Sumber :(SNI 03-1974-1990, 1990)(Hunggurami, 2017)

\subsection{Pengujian Nilai Absorsi}

Pengujian daya serap beton adalah kemampuan bahan dalam menyerap air. Bobot isi adalah perbandingan massa dalam keadaan kering dengan bobot dalam kondisi jenuh air. Daya serap air tinggi akan berpengaruh pada pamasangan paving beton berpori dan adukan karena air pada aduka di resap oleh agregat puntung rokok filter. Sehingga daya resap yang tinggi disebabkan oleh besarnya kadar pori. Untuk mengatahui seberapa cepat beton tersebut dapat menyerap air maka dilakukan pengujian ketika beton dalam keadaan kering lalu direndam dengan melihat penyerapan air pada waktu periode tertentu seperti pada waktu 1/4 jam, 1 jam, 4 jam dan 24 jam. Besarnya absorpsi pada paving block sesuai ASTM adalah :

At $=($ Wt-W0) $x 10000 / L 1 \times L 2$

$\mathrm{Wt}=$ berat benda uji pada waktu $\mathrm{T}$ (gram).

$\mathrm{W} 0=$ berat tetap awal benda uji (gram).

Sumber : SNI $1970: 2008$

\subsection{Pengujian Berat Jenis Beton}

Pengujian berat jenis beton dengan cara menimbang berat solid lalu membaginya dengan volume beton maka terbentuk nilai berat jenis beton. Sehigga di rumuskan sebagai berikut:

berat jenis $(\gamma)=\underline{\mathrm{W}}$

Dimana : 
$\mathrm{W}=$ Berat Total $(\mathrm{Kg})$

$\mathrm{V}=$ Volume Total $\left(\mathrm{m}^{3}\right)$

\section{HASIL DAN PEMBAHASAN}

\subsection{Hasil Pemeriksaan Uji Agregat}

Material dan bahan yang digunakan dalam penelitian ini meliputi Semen portland, air, limbah puntung rokok filter fillter yang berfungsi sebagai pengganti agregat kasar, pasir. Sebelum digunakan untuk membuat benda uji, material dan bahan dtersebut harus terlebih dahulu dilakukan pemeriksaan karakteristiknya. Pemeriksaan ini dilakukan di Laboratorium Teknik Sipil Universitas Kadiri. Hasil rekapitulasi peeriksaan awal agregat disajikan dalam tabel seperti di bawah ini.

Tabel 1: Rekapitulasi Pemeriksaan Karakteristik Agregat Halus

\begin{tabular}{|c|l|c|c|c|}
\hline NO & Karakteristik Agregat & interval Spesifikasi & Hasil uji & keterangan \\
\hline 1 & kadar air & $2 \%-5 \%$ & $2,79 \%$ & Memenuhi \\
\hline 2 & Berat Volume & $1,6-1,9 \mathrm{~kg} /$ liter & $1,61 \mathrm{Kg} / \mathrm{Liter}$ & Memenuhi \\
\hline 3 & Absorsi & Maks $2 \%$ & $0,81 \%$ & Memenuhi \\
\hline & Berat Jenis & $1,6-3,3$ & 2,48 & Memenuhi \\
\hline & a. Bj. Curah & $1,6-3,3$ & 2,5 & Memenuhi \\
\hline & b. Bj. Kering Permukaan & $1,6-3,3$ & 2,53 & Memenuhi \\
\hline & c. Bj. Semu & $1,5-3,8$ & 2 & Memenuhi \\
\hline 4 & Modulus Kehalusan & Maks $5 \%$ & $2,40 \%$ & Memenuhi \\
\hline 5 & Kadar Lumpur & &
\end{tabular}

\subsection{Hasil Perhitungan Rencana Campuran (JobMix Design)}

Dalam penelitian ini, perhitungan komposisi campuran yang digunakan dalam pembuatan benda uji mengacu pada SNI 7394 : 2008 tentang adukan beton setiap $1 \mathrm{~m}^{3}$. Mutu Beton yang digunakan yaitu K-250 dengan target hasil adalah K-100. Dengan 5 buah benda uji untuk beton 
modifikasi dengan puntung rokok filter. Dengan perbandingan antara berat jenis limbah puntung rokok filter fillter dengan berat jenis batu belah di rumuskan komposisi material seperti bentuk tabel seperti di bawah ini

Tabel 2: Komposisi Material Beton Limbah Puntung rokok filter Untuk Kebutuhan tiap $1 \mathrm{~m}^{2}$

\begin{tabular}{|c|l|c|c|c|c|}
\hline \multicolumn{5}{|c|}{ Perencanaan Job Mix Modifikasi dari limbah puntung rokok filter } \\
\hline NO & $\begin{array}{c}\text { Material Mix } \\
\text { K-125 } \\
\text { SNI 7394-2008 }\end{array}$ & Berat & Sat. & Presentase & Sat. \\
\hline 1 & Semen & 2 & $\mathrm{~K}$ & 26,6 & $\%$ \\
\hline 2 & Air & 2 & $\mathrm{~K}$ & 14,9 & $\%$ \\
\hline 3 & Puntung rokok filter & 148, & $\mathrm{~K}$ & 10,32 & $\%$ \\
\hline 4 & Pasir $\quad$ Total & 8 & $\mathrm{~K}$ & 48,0 & $\%$ \\
\hline
\end{tabular}

Sumber : Data diolah

\subsection{Hasil Pengujian Kuat Tekan Benda Uji}

Pengujian kuat tekan pada benda uji beton menggunakan alat kuat tekan hidrolis dengan kuat tekan mencapai 500 ton. Benda uji yang dipakai berdimensi 15 x 15 x $15 \mathrm{~cm}$ dengan umur 28 hari. Tes kuat tekan ini berdasarkan SNI 03-1974-1996.

Data yang di hasilkan dari alat test kuat tekan maka akan diolah seperti contoh di bawah ini :

$\mathrm{K}=\mathrm{P} / \mathrm{A}$

$$
\mathrm{K}=\frac{26000 \mathrm{~kg}}{225 \mathrm{~cm}^{2}}=115,56 \mathrm{Kg} / \mathrm{cm}^{3}
$$

Tabel 3: Tabel Test Kuat Tekan Beton Modifikasi Limbah Puntung rokok filter

\begin{tabular}{|c|c|c|c|c|c|}
\hline NO & Benda Uji & $\begin{array}{c}\text { Angka Dial } \\
\text { Newton }\end{array}$ & $\begin{array}{c}\text { Angka Dial di } \\
\text { Jadikan Kg }\end{array}$ & $\begin{array}{c}\text { Luas penampang 15 x } \\
15 \mathrm{~cm}(\mathrm{~A})\end{array}$ & $\begin{array}{c}\text { Hasil test ( K ) } \\
\text { Kuat Tekan } \\
\left(\mathrm{Kg} / \mathrm{cm}^{2}\right)\end{array}$ \\
\hline 1 & Sampel 1 & 26 & 26000 & 225 & 115,56 \\
\hline 2 & Sampel 2 & 19 & 19000 & 225 & 84,44 \\
\hline 3 & Sampel 3 & 24 & 24000 & 225 & 106,67 \\
\hline 4 & Sampel 4 & 24,5 & 24500 & 225 & 108,89 \\
\hline 5 & Sampel 5 & 19,5 & 19500 & 225 & 86,67 \\
\hline \multicolumn{6}{|c|}{ rata-rata } \\
\hline
\end{tabular}

Sumber : Data diolah

\subsection{Hasil Pengujian Absorsi}

Pengujian absorsi dilakukan ketika beton berumur 25 hari dan di angkat dari proses curing lalu di diamkan 24 jam hingga beton kering, baru kita lakukan tes absorsi dengan pengambilan data ketika beton di rendam selama $1 / 4 \mathrm{jam}, 1$ jam, 4 jam hingga 24 jam, data yang di hasilkan sebagai berikut. 
At $=(\mathrm{Wt}-\mathrm{W} 0) \times 10000 /(\mathrm{L} 1 \times \mathrm{x} 2)$

At $=(4,900-4,790) \times /(15 \times 15)$

$\mathrm{Wt}=$ berat benda uji pada waktu $\mathrm{T}(\mathrm{Kg})$.

$\mathrm{W} 0=$ berat tetap awal benda uji $(\mathrm{Kg})$.

L1 $x$ L2 = luas penampang beton $\left(\mathrm{cm}^{2}\right)$

Tabel 4: Tabel Test Absorsi Beton Limbah Puntung rokok filter

\begin{tabular}{|r|c|c|c|c|c|r|rr|r|r|}
\hline \multirow{2}{*}{ Benda uji } & \multicolumn{9}{|c|}{ Berat Waktu Perendaman } & \multicolumn{4}{c|}{ Hasil Absorsi (liter) } \\
\cline { 2 - 11 } & Berat Kering & 1/4 Jam & 1 Jam & 4 Jam & 24 Jam & 1/4 jam & 1 jam & 4 & jam & 24 jam \\
\hline Sampel 1 & 4,7 & 4,900 & 5,065 & 5,170 & 5,485 & 0,11 & 0,27 & 0,38 & 0,69 \\
\hline Sampel 2 & 4,8 & 4,935 & 5,100 & 5,205 & 5,520 & 0,11 & 0,27 & 0,38 & 0,69 \\
\hline Sampel 3 & 4,8 & 4,975 & 5,140 & 5,245 & 5,560 & 0,11 & 0,28 & 0,38 & 0,70 \\
\hline Sampel 4 & 4,7 & 4,880 & 5,020 & 5,125 & 5,465 & 0,13 & 0,27 & 0,38 & 0,72 \\
\hline Sampel 5 & 4,8 & 4,930 & 5,060 & 5,165 & 5,505 & 0,11 & 0,24 & 0,34 & 0,68 \\
\hline \multicolumn{19}{|c|}{ Rata-Rata } & 0,11 & 0,26 & 0,37 & 0,69 \\
\hline
\end{tabular}

Sumber : Data diolah

\subsection{Hasil Pengujian Angka Pori}

Pengujian angka pori yaitu angka yang menunjukkan perbandingan antara volume rongga dan volume butiran, hasil dari pengujian ini akan disajikan sebagai berikut.

$$
\operatorname{angka~pori~}(\mathrm{e})=\frac{\mathrm{Vv}}{\mathrm{Vs}_{\mathrm{s}}}
$$

Vs

Tabel 5: Tabel hasil perhitungan angka pori beton modifikasi limbah puntung rokok filter.

\begin{tabular}{|c|l|c|c|c|c|}
\hline NO & Benda Uji & $\begin{array}{c}\text { Volume Total } \\
(\mathrm{V}) \\
\mathrm{c}\end{array}$ & $\begin{array}{l}\text { Volume Solid (Vs) } \\
\mathrm{cm}^{3}\end{array}$ & $\begin{array}{c}\text { Volume Rongga (Vv) } \\
\mathrm{cm}^{3} \\
\text { V - }\end{array}$ & $\begin{array}{c}\text { Angka Pori } \\
(\mathrm{e}) \text { Vv } \\
\text { Vs }\end{array}$ \\
\hline 1 & Sampel 1 & 337 & 2624, & 750,608766 & 0,2860 \\
\hline 2 & Sampel 2 & 337 & 2628, & 746,368039 & 0,2839 \\
\hline 3 & Sampel 3 & 337 & 2630, & 744,286287 & 0,2829 \\
\hline 4 & Sampel 4 & 337 & 2610, & 764,669927 & 0,2929 \\
\hline 5 & Sampel 5 & 337 & 2634, & 740,587045 & 0,2811 \\
\hline \multicolumn{5}{|c|}{ angka pori } & \\
\hline
\end{tabular}

Sumber : Data diolah

\subsection{Hasil Pengujian Nilai Porositas}

Nilai porositas beton adalah kemampuan beton dalam menyerap air berkaitan dengan tingkat kepadatannya, Hasil pengujian porositas pada benda uji beton modifikasi dan beton normal disajikan dalam bentuk tabel sebagai berikut : Rumus untuk mencari nilai porositas :

$$
\text { porositas }(\mathrm{n})=\frac{\mathrm{E}}{1+\mathrm{e}}
$$

Tabel 6: Tabel hasil perhitungan porositas beton modifikasi dari limbah puntung rokok filter. 


\begin{tabular}{|c|c|c|c|}
\hline NO & Benda Uji & $\begin{array}{c}\text { Angka Pori (e) } \mathrm{Cm}^{3} \\
\text { Vv } / \text { Vs }\end{array}$ & $\begin{array}{c}\text { Porositas (n) } \\
\mathrm{e} /(1+\mathrm{e})\end{array}$ \\
\hline 1 & Sampel 1 & 0,2860 & 0,222403 \\
\hline 2 & Sampel 2 & 0,2839 & 0,221146 \\
\hline 3 & Sampel 3 & 0,2829 & 0,220529 \\
\hline 4 & Sampel 4 & 0,2929 & 0,226569 \\
\hline 5 & Sampel 5 & 0,2811 & 0,219433 \\
\hline
\end{tabular}

Sumber : Data diolah

\section{KESIMPULAN}

Berdasarkan penelitian kuat tekan, uji absorsi, uji berat jenis, angka pori,derajat kejenuhan dan porositas yang telah dilakukan dan hasil analisa data yang telah didapatkan dari pengamatan tersebut, Penelitian tentang pemanfaatan limbah puntung rokok fillter terhadap kuat tekan dan absorpsi uji berat jenis, angka pori,derajat kejenuhan dan porositas ini dilakukan di Laboratorium Teknik Sipil Universitas Kadiri selama dua bulan.

maka dapat diambil kesimpulkan sebagai berikut :

1. Hasil pengujian kuat tekan beton dengan penggantian agregat kasar dengan limbah puntung rokok fillter pada umur beton 28 hari memiliki rata-rata yang berbeda, untuk nilai kuat tekan beton dengan campuran agregat kasar limbah pontung rokok hanya mencapai K-100,44 dengan nilai kuat tekan tertinggi mencapai K-115,56

2. Pada pengujian Absorpsi didapatkan rata-rata nilai penyerapan air dalam waktu berturutturut yaitu 1/1/4 jam, 1 jam, 4 jam, 24 jam di dapat hasil sebesar 0,116 liter, 0,269 liter, 0,374 liter, 0,699 liter

3. Dari penelitiaan yang telah dilakukan diperoleh nilai dari berat jenis beton, angka pori beton, nilai porositas, derajat kejenuhan sebagai berikut :

a. Dari pengujian berat jenis yang telah di lakukan bahwa beton dari limbah puntung rokok fillter memiliki berat jenis rata-rata $1831,11 \mathrm{Kg} / \mathrm{m}^{3}$,

b. Pada pengujian angka pori untuk beton dengan agregat kasar limbah puntung rokok fillter mencapai nilai rata- rata 0,2854

c. Hasil dari pengujian porositas di dapat nilai untuk beton dengan agregat kasar limbah puntung rokok mencapai 0,222016,

\section{DAFTAR PUSTAKA}

[1] A D Limantara, A Widodo, S Winarto, L. D. K. and S. W. M. (2017). „Optimizing The Use Of Natural Gravel Brantas River As Normal Concrete Mixed With Quality $\mathrm{Fc}=19$. $3 \mathrm{Mpa}^{\mathrm{ee}}$, IOP Conference Series, (Earth and 
Environmental Science PAPER). doi: 10.1088/1755-1315/140/1/012104.

[2] Bilqis, Sheba. 2012. Studi Kuat Tekan Pada Mortar Yang Mengandung Rice Husk Ash (Rha) Dan Concrete Sludge Waste (Csw) Dengan Komposisi Semen, Agregat Halus 1:3. Depok: Departemen Teknik Sipil, Universitas Indonesia.

[3] Defoirdt N, Biswas S, De Vriese L, Ngoc Tran LQ, Van Acker J, Ahsan W, Gorbatikh L, Van Vuure A, Verpoest I. 2010. “Assessment Of The Tensile Properties Of Coir, Bamboo And Jute Fibre". Compos A 41:588-595

[4] Dimitrioglou, N, P E Tsakiridis, N S Katsiotis, M S Katsiotis, P Perdikis, and M Beazi. 2015. "Production and Characterization of Concrete Paving Blocks Containing Ferronickel Slag as a Substitute for Aggregates.” Waste and Biomass Valorization. Springer Netherlands. https://doi.org/10.1007/s12649-015-9465-1.

[5] Barros, Joaquim A O, Liberato Ferrara, and Enzo Martinelli. 2017. Recent Advances on Green Concrete for Structural Purposes. Edited by Enzo Martinelli. Milan: Springer International Publishing. https://doi.org/10.1007/978-3-319-56797-6.

[6] Frias M, Savastano H, Villar E, Sanchez de Rojas MI, Santos S. 2012. "Characterization And Properties Of Blended Cement Matrices Containing Activated Bamboo Leaf Wastes". Constr Build Mater 34:1019-1023

[7] Ghavami K. 1995. "Ultimate Load Behaviour Of Bamboo-Reinforced Lightweight Concrete Beams". Cem Concr Compos 17:281-28

[8] SNI 1970:2008.Medote PengujianBeratJenis Dan Penyerapan Agregat Halus. Departemen Pekerjaan Umum. Jakarta.

[9] SNI 03-2847-2002. Tata Cara Perhitungan Struktur Beton Untuk Bangunan Gedung. Bandung.

[10] SNI 02-6820-2002.Spesifikasi AgregatHalusUntukPekerjaanAdukan Dan

PlesteranDenganBahanDasarSemen.BadanStandarisasiNasional.Jakarta.

[11] SNI 03-1971-1990.1990. Metode Pengujian Kadar Air Agregat. Badan Standarisasi Nasional. Jakarta.

[12] SNI 15-2049-2004. 2004. Semen Portland. Badan StandarisasiNasional. Jakarta.

[13] Tjokrodimulyo, K. 1995.Teknologi Beton.JurusanTeknikSipilUGM.Yogyakarta.

[14] Owaid, H. M., Hamid, R., Abdullah, S. R. S., Kofli, N. T., \& Taha, M. R. (2013). 
Physical and mechanical properties of high performance concrete with alum sludge as partial cement replacement. Jurnal Teknologi (Sciences \& Engineering), 65, 105-112.

[15] Mydin, M. O., Sahidun, N. S., Yusof, M. M., \& Noordin, N. M. (2015). Compressive, Flexural And Splitting Tensile Strengths Of Lightweight Foamed Concrete With Inclusion Of Steel Fibre. Jurnal Teknologi, 75(5). 